\title{
Straight Motion: A Mobile Application for Learning Linear Motion
}

\author{
Elisabeth Pratidhina ${ }^{1}$, Ferina Rizky Yuliani ${ }^{2}$, Johannes V D Wirjawan ${ }^{3}$, Herwinarso ${ }^{4}$, \\ Budijanto Untung ${ }^{5}$ \\ \{elisa.founda@ukwms.ac.id ${ }^{1}$, ferina.rizky@gmail.com², wirjawan@ukwms.ac.id ${ }^{3}$, \\ herwinarso@ukwms.ac.id ${ }^{4}$, budijanto@ukwms.ac.id $\left.{ }^{5}\right\}$ \\ Department of Physics Education, Widya Mandala Surabaya Catholic University, J1 Kalijudan 37 \\ Surabaya, Indonesia, $60114^{1,2,3,4,5}$
}

\begin{abstract}
Mobile phone technology has been developed tremendously in the last two decades. The smartphone's emergence has shifted the primary function of a mobile phone because it provides various advanced features. Multiple features in the smartphone are the potential to be utilized in education. In this paper, we report a study that aims to develop a Straight Motion application, a mobile application designed as a learning resource on linear motion topics. The application is targeted to high school students as a resource for prelecture preparation or post-lecture review and individual study. Straight Motion application is evaluated by an expert in physics and physics education. According to the evaluation, the application is feasible to be used by high school students in learning physics. We also conduct field testing, which involves 63 -grade $10^{\text {th }}$ students. To investigate the learning improvement, we give pre-and post-test to students before and after they use Straight Motion for learning linear motion. The calculated normalized gain is 0.56 , which can be classified as medium gain. Moreover, students also give an excellent response to the use of Straight Motion in the learning process.
\end{abstract}

Keywords: high school physics, learning media, mobile app

\section{Introduction}

One of the vast developed technology is the mobile phone. Nowadays, the mobile phone's primary function as a communication device has been shifted with smartphone emergence. In current society, the smartphone is one of the essential technology used by people around the world. Smartphone typically has a touch screen, internet access, and the capability to install applications, cameras, media players, sensors, and navigation function [1]. The smartphone can be regarded as a pocket computer.

Advanced technology in mobile devices, including smartphones, evokes educators, and researchers to promote teaching and learning [2-4]. Mobile devices can make the classroom more interactive and engaging [5,6]. Several studies indicate that mobile learning is motivating for students [7,8]. Mobile devices can also be used to achieve anytime, anywhere, and ubiquitous learning [9]. With mobile devices, teaching and learning are not restricted by time and place. Students can extend their learning activity at a home where learning can occur naturally [10].

There has been an excessive attempt to include smartphones in the learning activity, including in physics disciplines. Physics educators have used smartphones to engage students 
in a physics experiment class [11-13]. Smartphones have various sensors that can be used for precise measurement tools such as magnetometer [14], accelerometer [15], gyroscope [12], and light sensor [16]. Using a smartphone in a physics experiment is the potential to build meaningful learning for students.

Smartphone has the capability for installation of applications. Educators can build applications as multimedia in learning physics [17,18]. Multimedia can foster learning physics's effectiveness because it can present visualizations of physical concepts and related examples of physical phenomena. Also, educators can include physics simulation in smartphone application [19-21]. Simulation has some advantages, such as allow students to experience indirect-data collection and analysis, support visualization of conceptual entities, and develop students' critical thinking through the inquiry process at public places and time. Some researchers also develop educational games in the mobile application to gain students' interest and motivation in learning physics [22-24].

Young learners are familiar with digital technology. They are often called digital natives. They are known as digitally literate, connected multitasker, and discovery learners [25]. The smartphone may create a flexible and personalized learning process suitable for young learners like high school students. In this study, we design smartphone applications as a learning resource for high school students. We name it "Straight Motion." Straight Motion application aims to help students in learning Linear Motion. We combine multimedia and simulation in one application. Straightforward Motion application includes material, simulation, and problem exercise. Students can use the application as a resource for pre-lecture preparation or postlecture review and individual study.

\section{Method}

This research aims to develop Straight Motion as a learning media on the topics of linear motion. The study is started with need assessment and analysis of the characteristic of learners and curriculum. The targeted learner is high school students in grade 10 who are mostly digital native and familiar with smartphone technology. We design the learning resource according to National Curriculum in Indonesia.

We construct the material based on the learner, need, and curriculum analysis. In brief, the concept map of the designed material is shown in Figure 1. We create the prototype of the Straight Motion application in the Adobe Animate CC software [26].

After we construct the Straight Motion prototype, the next step is a series of developmental testing. In developmental testing, the prototype of the Straight Motion is evaluated through expert appraisal and field testing. A revision follows each step of developmental testing. The expert appraisal involves experts in physics and physics education, both lecturers in the Department of Physics Education.

We carry out a pilot study in a private high school in Indonesia to implement the developed application and investigate its impact on students' learning achievement. Sixty-three students in grade 10 participate in the pilot study. Pre- and post-test are conducted before and after the participants learn linear motion with the application. The comparison between the results of both tests is used to determine the learning improvement. We use normalized gain score $\langle g\rangle$ as the parameter of the students' learning improvement. The formula to calculate $\langle g\rangle$ is:

$$
\langle g\rangle=\frac{\%\left\langle S_{f}\right\rangle-\%\left\langle S_{i}\right\rangle}{100-\%\left\langle S_{i}\right\rangle}
$$


where $\left\langle S_{i}\right\rangle$ and $\left\langle S_{f}\right\rangle$ are pre-and post-test class averages, respectively. Hake (1998) divides $\langle g\rangle$ into three categories, i.e., high for $\langle g\rangle \geq 0.7$; medium for 0.7$\rangle\langle g\rangle \geq 0.3$, and low for $\langle g\rangle<0.3$.

After using the application, students also fill a questionnaire about their opinion on the developed application. They also write their suggestion to improve the quality of the application.

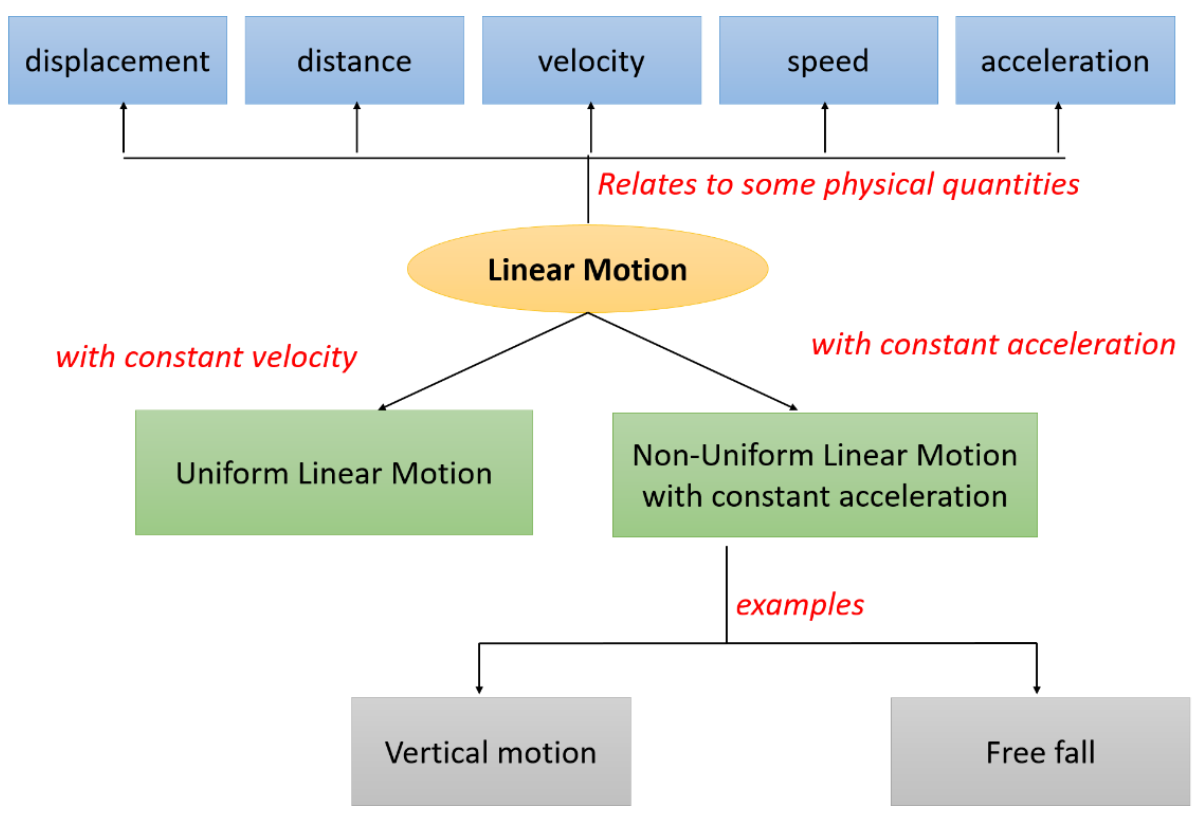

Fig 1. The concept map of the material

\section{Result and Discussion}

The Straight Motion application has three main features, i.e., material, simulation, and problem exercise, such as presented on the homepage of the application (see Figure 2). The material discusses quantities in kinematics, uniform, and non-uniform linear motion with constant acceleration. Examples of linear motion in real physical phenomena such as vertical motion and free-falling are also discussed. We explain linear motion characteristics through various physical representations, such as verbal explanation, mathematical expression, and graph. Moreover, illustration and animation are also inserted. Screenshots of the material menu are presented in Figure 3. 

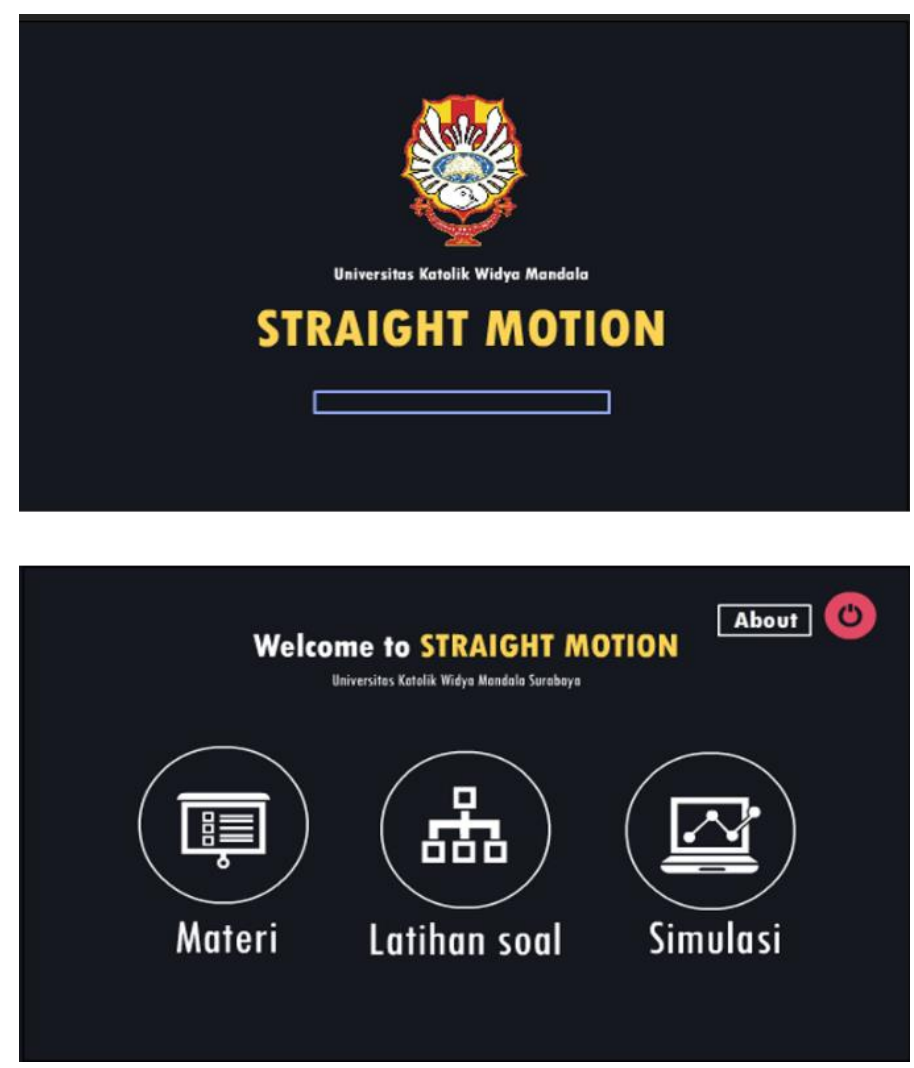

Fig 2. The screenshot of the homepage 

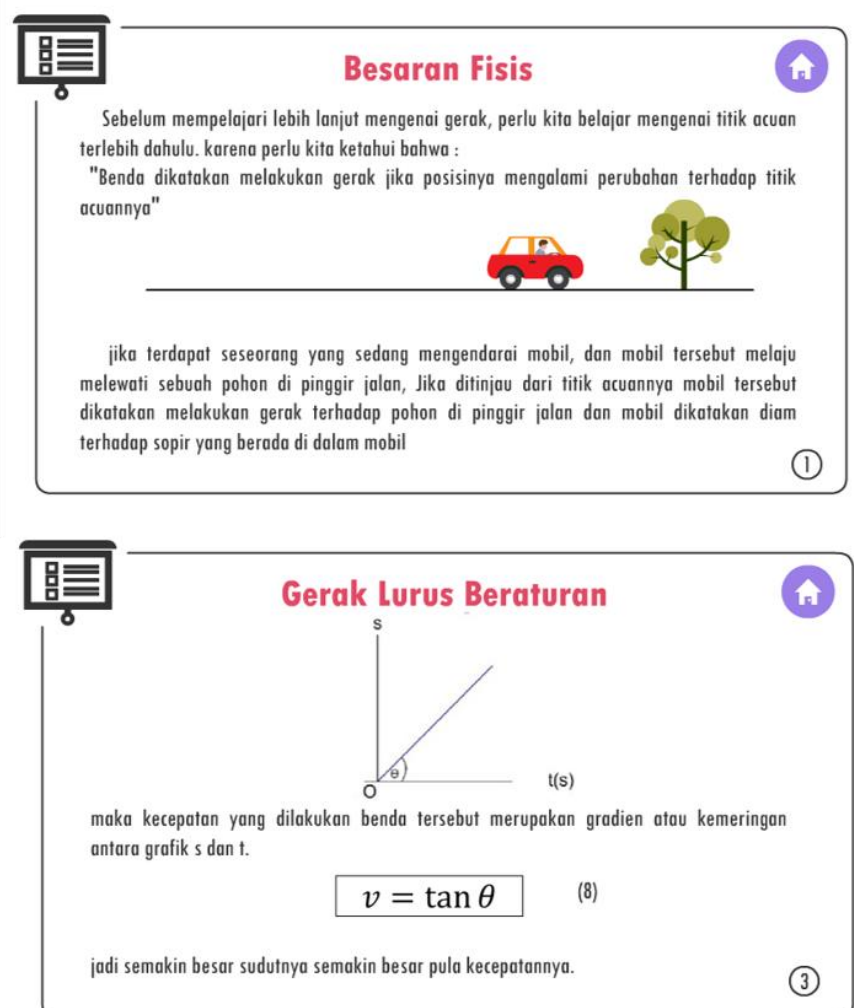

jadi semakin besar sudutnya semakin besar pula kecepatannya.

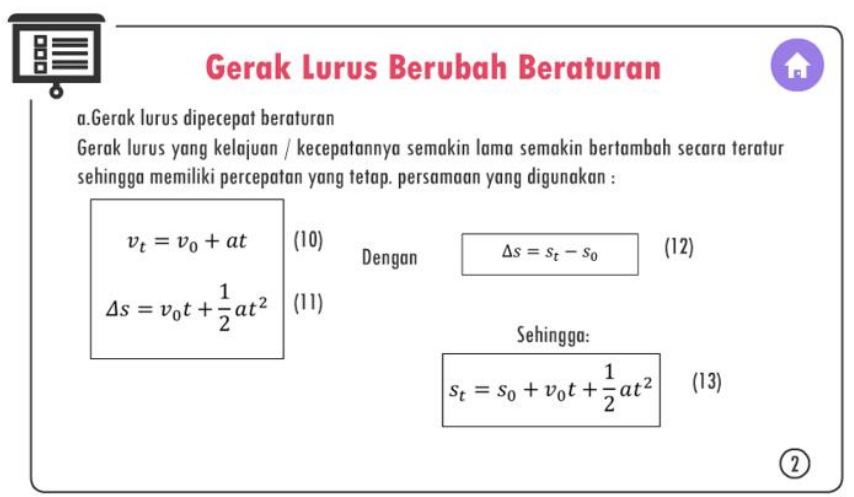

Fig 3. The screenshot of the material menu

This Straight Motion is also accommodating the Simulation menu. The simulation aims to give students experience in investigating the characteristics of some types of linear motion. There are three simulations in this application. They are about a car that moves with constant velocity, a vehicle that moves with constant acceleration, and a free-falling stone. In investigating the characteristic of uniform linear motion, students are asked to do the simulation with a car (see Figure 4). In the simulation, students can vary the moving distance of a vehicle 
up to five times. The time required by the car will be shown up, and students need to write down the time for the respective moving distance. Students are asked to plot a graph between space and time and compare it to the mathematical expression. Students are guided to find the relation among physical quantities in various types of linear motion through simulation.
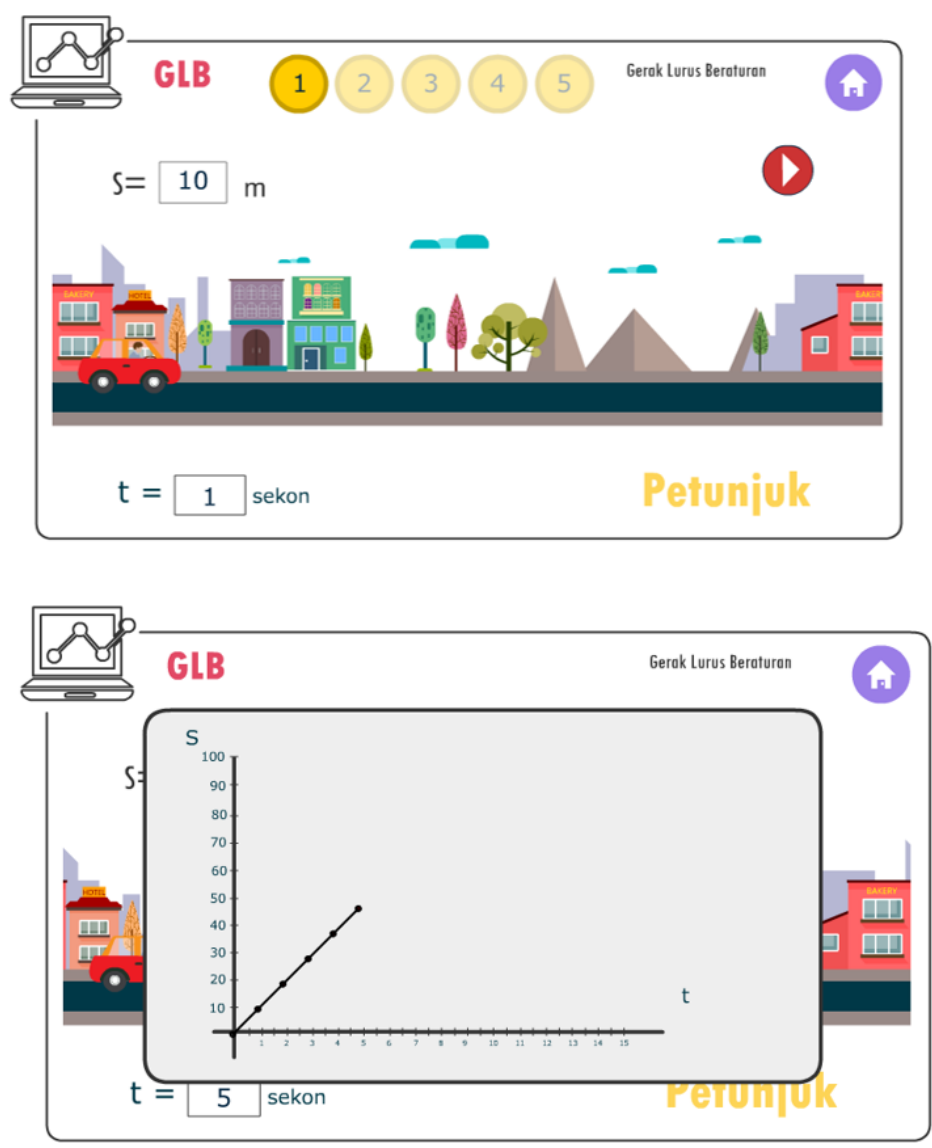

Fig 4. The screenshot of the simulation about uniform linear motion

For individual learning activities, students should be able to do self-evaluation of their studies. Thus, the Straight Motion application also provides problem exercise, as illustrated in Figure 5. In this menu, students can answer some multiple-choice questions and get feedback directly. 

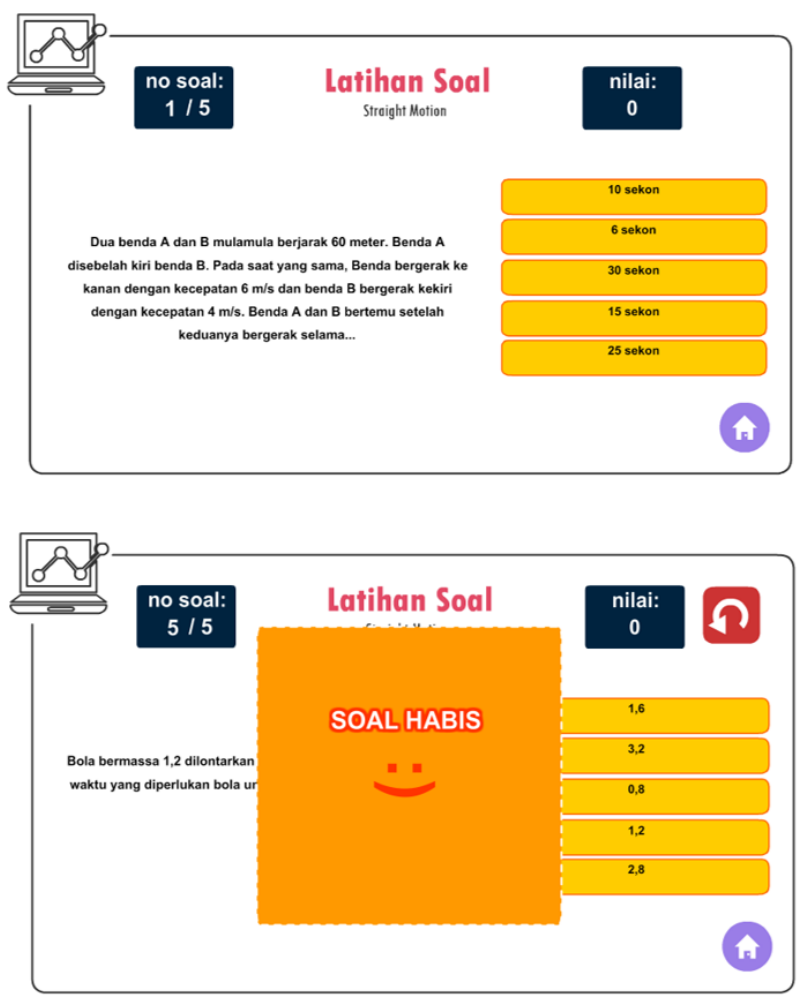

Fig 5. The screenshot of the problem exercise menu

\subsection{Developmental Testing}

Experts in physics and physics education evaluate the prototype of the Straight Motion application. The experts give several ideas to make the prototype becomes better. We accommodate some of those ideas in the revision process. After a couple of revisions, overall experts provide an excellent rating in content, instructional, layout, language, and accessibility (see Table 1).

Table 1. Expert Evaluation on the Prototype of the Straight Motion Application

\begin{tabular}{lcc}
\hline \multicolumn{1}{c}{ Aspects } & Score* & Criteria \\
\hline Material/Content & 3.89 & Excellent \\
Instructional & 3.72 & Excellent \\
Layout quality & 3.57 & Excellent \\
Accessibility & 3.36 & Excellent \\
Language & 3.66 & Excellent \\
\hline
\end{tabular}

* max score: 4.0

We carry out field testing in an Indonesian private high school. We calculate the N-gain score with the formula in equation (1) to determine the students' learning improvement. Figure 6 shows the comparison between average pre-and post-test scores. The average $\mathrm{N}$-gain score is 0.56 (see Table 2), which can be interpreted as a medium improvement [27]. 
Although in this research, we have not compared our applied learning method with others, the current result aligns with previous studies that emphasize the advantage of using multimedia, especially mobile learning applications in physics learning $[19,28]$. Multimedia enable students to get information in more various formats. Through visualization in multimedia, physical concepts can be presented in a more informative way to students.

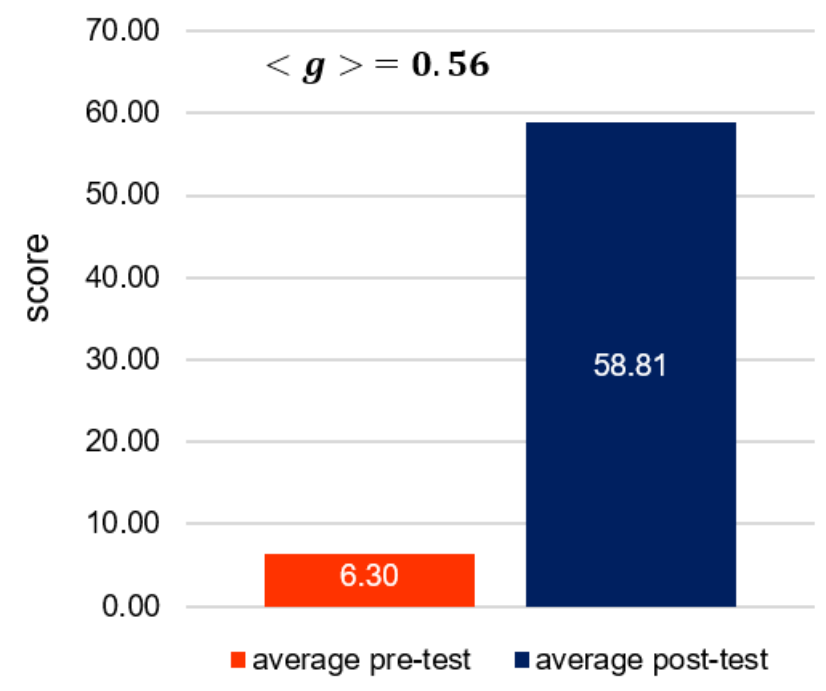

Fig 6. Result of pre-and post-test

Table 2. The comparison between the pre-and post-test score

\begin{tabular}{cccc}
\hline Average Pre-Test & Average Post-Test & $\begin{array}{c}\text { Normalized Gain } \\
\text { Score, }\langle\mathrm{g}\rangle\end{array}$ & Criteria \\
\hline 6.30 & 58.81 & 0.56 & medium \\
\hline
\end{tabular}

Table 3. Students' rating of the quality of the Straight Motion application

\begin{tabular}{ccc}
\hline Aspects & Average Score & Criteria \\
\hline Material & 3.23 & Good \\
Instructional & 3.31 & Good \\
Layout quality & 3.31 & Good \\
Accessibility & 3.30 & Good \\
\hline
\end{tabular}

During the field testing, we give a questionnaire to students. As shown in Table 3, students provide an excellent response to every straight motion aspect. Students provide fantastic reactions to the clarity of the material. From the instructional element, the application is also useful. It is helpful for students in understanding the concepts of linear motion. The layout of the application has a good quality. Moreover, accessibility is also good. There is no frequent bugging while opening the application. 


\section{Conclusion}

In summary, we have developed Straight Motion, an Android-based learning application on Linear Motion topics. Based on the experts' evaluation, the learning resource helps students learn the linear motion. Besides, field testing indicates students' learning improvement after using Straight as a learning resource. A good response is given to the use of Straight Motion applications. The mobile-based learning resource is convenient and helpful for students. This study still has some limitations. The investigated learning improvement in this study only covers the cognitive domain. For further research, we need to consider the affective and psychomotor domains. Moreover, field testing may be improved by using experimental and control classes.

Acknowledgments. This study is supported by the Indonesian Ministry of Education and Culture under the PTUPT grant with contract number: 130V/WM1.5/N/2020.

\section{References}

[1] Haug S, Castro RPAZ, Kwon MIN, Filler A, Kowatsch T, Schaub MP. Smartphone Use and Smartphone Addiction Among Young People in Switzerland. J Behav Addict. 2015;4(4):299-307.

[2] Zydney JM, Warner Z. Mobile Apps for Science Learning : Review of Research. Comput Educ [Internet]. 2016;94:1-17. Available from: http://dx.doi.org/10.1016/j.compedu.2015.11.001

[3] Odabasi M, Uzunboylu H, Popova O V, Kosarenko NN, Ishmuradova II. Science Education and Mobile Learning: A Content Analysis Review of the Web of Science Database. Int J Emerg Technol Learn. 2019;14(22):4-18.

[4] Qureshi MI, Khan N, Gillani SMAH, Raza H. A Systematic Review of Past Decade of Mobile Learning: What We Learned and Where to Go. Int J Interact Mob Technol. 2020;14(6):67-81.

[5] Shen R, Wang M, Pan X. Increasing Interactivity in Blended Classrooms Through A Cutting-Edge Mobile Learning System. Br J Educ Technol. 2008;39(6):1073-86.

[6] Razzaq A, Samiha YT, Anshari M. Smartphone Habits and Behaviors in Supporting Students Self-Efficacy. Int J Emerg Technol Learn. 2018;13(2):94-109.

[7] Schmitz B, Klemke R, Specht M. Effects of Mobile Gaming Patterns on Learning Outcomes : A Literature Review. Int J Technol Enhanc Learn. 2012;4:345-58.

[8] Hsu Y, Ching Y. Mobile Computer-Supported Collaborative Learning: A Review of Experimental Research. Br J Educ Technol. 2013;44(5):E111-4.

[9] Zhang JHK. Examining mobile learning trends 2003 - 2008 : a categorical meta-trend analysis using text mining techniques. J Comput High Educ. 2012;24:1-17.

[10] Huang Y, Lin Y, Cheng S. Effectiveness of a Mobile Plant Learning System in a Science Curriculum in Taiwanese Elementary Education. Comput Educ [Internet]. 2010;54(1):4758. Available from: http://dx.doi.org/10.1016/j.compedu.2009.07.006

[11] Kubsch M, Nordine J, Hadinek D. Using Smartphone Thermal Cameras to Engage Students' Misconceptions About Energy. Phys Teach. 2017;55:504.

[12] Oprea M, Miron C. Mobile Phones in The Modern Teaching of Physics. Rom Reports Phys. 2014;66(4):1236-52.

[13] Hochberg K. Using Smartphones as Experimental Tools - Effects on Interest, Curiosity, and Learning in Physics Education. J Sci Educ Technol. 2018;27(5):385-403. 
[14] Arribas E, Escobar I, Suarez CP. Measurement of the magnetic field of small magnets with a smartphone: a very economical laboratory practice for introductory physics courses. Eur J Phys [Internet]. 2015;36(6):65002. Available from: http://dx.doi.org/10.1088/0143 0807/36/6/065002

[15] Vogt P, Kuhn J. Analyzing Simple Pendulum Phenomena with A Smartphone Acceleration Sensor. Phys Teach. 2012;50:439.

[16] Sans JA. Oscillations studied with the smartphone ambient light sensor. Eur J Phys. 2013;34:1349-54.

[17] Liliarti N, Heru K. Improving the Competence of Diagrammatic and Argumentative Representation in Physics through Android-based Mobile Learning Application. Int J Instr. 2018;11(3):106-22.

[18] Setiyadi A, Darma RS, Wilujeng I. Mathematical Representations Mapping of High School Students after Using Multimedia Learning Modules Assisted by an Android Smartphone. J Phys Conf Ser. 2019;1233:012049.

[19] Arista FS, Kuswanto H. Virtual Physics Laboratory Application Based on the Android Smartphone to Improve Learning Independence and Conceptual Understanding. Int J Instr. 2018;11(1):1-16.

[20] Astra IM, Nasbey H, Nugraha A. Development of an Android Application in the Form of a Simulation Lab as Learning Media for Senior High School Students. Eurasia J Math Sci Technol Educ. 2015;11(5):1081-8.

[21] Rani SA, Mundilarto, Warsono, Dwandaru WSB. Physics virtual laboratory: an innovative media in 21 st century learning. In: Journal of Physics: Conference Series. 2019. p. 022026.

[22] Khouna J, Ajana L, Rhazal A, Hajjami A El. Introducing Educational Games in the Teaching of Physics in Moroccan Secondary Schools. IOSR J Res Method Educ. 2017;7(4):19-28.

[23] Costa MC, Manso A. Design of a Mobile Augmented Reality Platform with Game-Based Learning Purposes. Information. 2020;11(13):127.

[24] Komalawardhana N, Panjaburee P. Proposal of Personalised Mobile Game from InquiryBased Learning Activities Perspective : Relationships Among Genders, Learning Styles , Perceptions , and Learning Interest. Int J Mob Learn Organ. 2018;12(1):55-76.

[25] Lai K, Hong K. Technology Use and Learning Characteristics of Students in Higher Education : Do Generational Differences Exist? Br J Educ Technol. 2014;46(4):725-73.

[26] Adobe. A new age for animation [Internet]. Adobe. 2020. Available from: https://www.adobe.com/sea/products/animate.html\#scroll

[27] Hake RR. Interactive-Engagement Versus Traditional Methods: A Six-Thousand-Student Survey of Mechanics Test Data for Introductory Physics Courses. Am J Phys [Internet]. 1998 Jan;66(1):64-74. Available from: http://aapt.scitation.org/doi/10.1119/1.18809

[28] Herwinarso H, Untung B, Wirjawan JVD, Pratidhina E. Development of Android App to Assist High School Students in Learning Physics Quantities and Measurement Principles. TEM J. 2020;9(1):292-5. 